\title{
Loop-mediated isothermal amplification (LAMP) detection of Babesia orientalis in water buffalo (Bubalus babalis, Linnaeus, 1758) in China
}

\author{
Lan He ${ }^{\mathrm{a}, \mathrm{b}}$, Yan-Qin Zhou ${ }^{\mathrm{b}}$, Marinda C. Oosthuizen ${ }^{\mathrm{c}, *}$, Jun-Long Zhao ${ }^{\mathrm{a}, \mathrm{b}, * *}$ \\ a State Key Laboratory of Agricultural Microbiology, Huazhong Agricultural University, Hubei, Wuhan 430070, China \\ ${ }^{\mathrm{b}}$ College of Veterinary Medicine, Huazhong Agricultural University, Hubei, Wuhan 430070, China \\ ${ }^{\mathrm{c}}$ Department of Veterinary Tropical Diseases, Faculty of Veterinary Science, University of Pretoria, Private Bag x04, 0110 Onderstepoort, South Africa
}

\section{A R T I C L E I N F O}

\section{Article history:}

Received 25 May 2009

Received in revised form 22 June 2009

Accepted 29 June 2009

\section{Keywords:}

Babesia orientalis

LAMP

18S rRNA

Babesiosis

\begin{abstract}
A B S T R A C T
Loop-mediated isothermal amplification (LAMP) is a rapid method with high specificity and efficiency under isothermal condition using a set of four specifically designed primers that recognize six distinct sequences on the target gene. In this study, a LAMP method was developed for specific detection of Babesia orientalis in water buffalo (Bubalus babalis, Linnaeus, 1758). Four primers were designed from the V4 hypervariable region of the $18 \mathrm{~S}$ rRNA gene of $B$. orientalis. Blood samples were collected from $B$. orientalis experimentally infected water buffalo as well as from 165 water buffalo from eight different regions of the Hubei province, south China. Genomic DNA was extracted, subjected to the LAMP assay and compared with results obtained using a previously described semi-nested PCR. The LAMP assay proofed to be $B$. orientalis specific and more sensitive than the semi-nested PCR. While previously B. orientalis had not been reported north of the Yangtse River, our results show that $B$. orientalis has spread to the north of the river. This could pose a serious threat to the water buffalo industry.
\end{abstract}

(c) 2009 Elsevier B.V. All rights reserved.

\section{Introduction}

Babesia orientalis causes water buffalo babesiosis, one of the most important diseases of buffalo in central and south China, annually resulting in enormous economic losses (Liu et al., 1997; Liu et al., 2005). It is a tick-borne, intraerythrocytic protozoan parasite; the disease is characterized by fever, anemia, icterus, haemoglobinuria and high mortality (Liu et al., 1986, 1987; Chen, 1989). Water buffalo (Bubalus babalis, Linnaeus, 1758) is the only mammalian host of $B$. orientalis (Liu et al., 1997). Rhipicephalus haemaphysaloides,

\footnotetext{
* Corresponding author at: Department of Veterinary Tropical Diseases, Faculty of Veterinary Science, University of Pretoria, Private Bag x04, 0110 Onderstepoort, South Africa. Tel.: +27 125298390.

** Corresponding author at: State Key Laboratory of Agricultural Microbiology, Huazhong Agricultural University, Sizhishan Street, Hubei, Wuhan 430070, China. Tel.: +86 2787281810.

E-mail addresses: marinda.Oosthuizen@up.ac.za (M.C. Oosthuizen), zhaojunlong@mail.hzau.edu.cn (J.-L. Zhao).
}

which is widely distributed in central and south China, is the only known tick vector for $B$. orientalis. It transmits the parasite to buffalo transovarially with the infective stage being the adult tick (Liu et al., 1997).

Although microscopic examination of thin blood smears has traditionally been used for the diagnosis of acute Babesia infections, it remains challenging to diagnose carrier animals using microscopic examinations due to the low sensitivity of the technique (Almeria et al., 2001). Several serological methods are available, but disadvantages include the occurrence of cross-reactions and the lack of discrimination between previous exposure and current infections (Wagner et al., 1992). Molecular techniques have been proven very useful in the detection and identification of many haemoparasites like the Theileria/Babesia group, and are based on species-specific PCR assays, many of which target the 18S rRNA gene (Caccio et al., 2000). Many PCR assays, including nested- and real-time PCR assays, have been described for the sensitive and specific detection of Theileria and Babesia species (Fahrimal et al., 1992; Figueroa 
et al., 1993; Smeenk et al., 2000; Almeria et al., 2001; Oliveira-Sequeira et al., 2005; Liu et al., 2007; Martins et al., 2008; Sibeko et al., 2008). These techniques, however, rely on the availability of expensive equipment such as thermocyclers. There is a need for the development of sensitive, simple, cost-effective, and rapid diagnostic techniques. Loop-mediated isothermal amplification (LAMP) may provide the answer. It is expected to amplify $10^{9}$ copies in less than $1 \mathrm{~h}$, with high specificity as four primers are used for the detection of six distinct sequences (Notomi et al., 2000). Most importantly, LAMP assays do not require any expensive or complicated equipment as a regular water bath or heating block is sufficient for the reaction to be performed in. Direct visual identification can also be observed using SYBR Green I under a UV lamp.

In this study, a LAMP method was developed for the specific detection of $B$. orientalis in water buffalo in China.

\section{Materials and methods}

\subsection{Collection of blood samples}

Two 1-year-old water buffalo, free of $B$. orientalis infection as confirmed with semi-nested PCR (Liu et al., 2007), were splenectomised 14 days prior to $B$. orientalis infection. The $B$. orientalis Wuhan strain, previously isolated from the Hubei province, China and preserved in liquid nitrogen (Liu et al., 2005), were used to infect the buffalo. Each buffalo was subcutaneously injected with $4 \mathrm{ml}$ of the $B$. orientalis infected blood (percentage of parasitized erythrocyte, PPE 1\%). Blood samples were collected every three days for 39 days post-infection and subjected to the LAMP assay and the semi-nested PCR, respectively. Additionally, blood films were taken from the ear vein, fixed with methanol, stained with Giemsa and examined for the presence of haemoprotozoan parasites.

Blood samples were also collected from 165 randomly selected water buffalo from eight different regions of the Hubei province, south China. All blood samples were collected in EDTA which were directly used or stored at $-20{ }^{\circ} \mathrm{C}$ until use.

B. orientalis (Wuhan strain) infected blood (Liu et al., 2005) was used as gold standard positive control. African buffalo (Syncerus caffer) blood samples originating from the Kruger National Park $(n=41)$ and Hluhluwe-iMfolozi Park $(n=25)$, South Africa were used as gold standard negative samples. Since there is no report of $B$. orientalis in Southern Africa, neither the tick vector of $B$. orientalis $(R$. haemaphysaloides) nor B. orientalis exist in Southern Africa, these were considered true $B$. orientalis negative samples.

\subsection{DNA extraction}

Genomic DNA of all samples was extracted from $200 \mu \mathrm{l}$ of blood using the QIAamp blood and tissue extraction kit (Qiagen, Hilden, Germany) following the manufacturer's instructions. DNA was eluted in $100 \mu$ l elution buffer and stored at $-20{ }^{\circ} \mathrm{C}$ until further analysis.

\subsection{LAMP assay}

\subsubsection{Primer design}

Four primers (Table 1 ) were designed based on the V4 hypervariable region of the $B$. orientalis $18 \mathrm{~S}$ rRNA gene (GenBank accession number AY596279) using the Primer Explorer V3 software package (http://primerexplorer.jp/ elamp3.0.0)

\subsubsection{Reaction conditions}

The LAMP reaction was performed in a total volume of $25 \mu \mathrm{l}$ containing $0.2 \mu \mathrm{M}$ each of $\mathrm{F} 3$ and B3, $0.8 \mu \mathrm{M}$ each of FIP and BIP, $400 \mu \mathrm{M}$ of each dNTP, $1 \mathrm{M}$ betaine (SIGMA), $20 \mathrm{mM}$ Tris- $\mathrm{HCl}$ (pH 8.8), $10 \mathrm{mM} \mathrm{KCl}, 10 \mathrm{mM}\left(\mathrm{NH}_{4}\right)_{2} \mathrm{SO}_{4}$ $2 \mathrm{mM} \mathrm{MgSO}_{4}, 0.1 \%$ Triton X-100, $2 \mathrm{mM} \mathrm{MgCl}_{2}$ and $1.0 \mu \mathrm{l}$ genomic DNA. The mixture was heated at $95{ }^{\circ} \mathrm{C}$ for $5 \mathrm{~min}$, chilled on ice; subsequently $1.0 \mu \mathrm{l}$ ( $8 \mathrm{U}$ ) Bst DNA polymerase large fragment (New England Biolabs, M0275) was added. It was incubated at $63.5{ }^{\circ} \mathrm{C}$ for $45 \mathrm{~min}$ and then heated at $80^{\circ} \mathrm{C}$ for $10 \mathrm{~min}$ to terminate the reaction. The LAMP products were subjected to $2 \%$ agarose gel electrophoresis, stained with ethidium bromide and visualized under ultraviolet light. In addition, $10 \mu$ l of SYBR Green I was added to the LAMP products and a positive reaction was visualized by the formation of a green colour. When no amplification occurred, the solution remained orange.

To confirm specificity, LAMP primer pair F3 and B3 amplicons, generated by conventional PCR, were cloned using the pMD18-T vector system (TaKaRa Bio Inc.) and sequenced.

DNA of several different Babesia and Theileria species, including $B$. orientalis, Babesia bovis, Babesia divergens, Babesia bigemina, Babesia gibsoni, Babesia caballi, Theileria mutans, Theileria velifera and Theileria parva was subjected to the LAMP assay in order to determine the analytical specificity of the assay. DNA from gold standard negative African buffalo was also tested.

\subsection{Semi-nested $P C R$}

The primers of semi-nested PCR were designed based on the sequence of the $18 \mathrm{~S}$ rRNA gene for $B$. orientalis

Table 1

Primers for LAMP and the semi-nested PCR.

\begin{tabular}{lll}
\hline Assay & Primer type & Sequence $\left(5^{\prime}-3^{\prime}\right)$ \\
\hline LAMP & F3 & TTTCAGCGTTGTGCGTGTG \\
& B3 & TAAATACGAATGCCCCAAC \\
& FIP & GCCTGCTTGAAACACTCTAATTTCTCTTTGGCCGTCTCACTTCGC \\
& BIP & GAGCATGGAATAATAGAGTAGGACCTCCATTACCAAGGTAACAAAACCAAC \\
Semi-nested PCR & P1 & AACCTGGTTGATCCTGCCAGTAGT \\
& B-P2 & TGAGAAACGGCTACCACA \\
& B-R2 & CACACGCACAACGCTGAA \\
\hline
\end{tabular}


(GenBank accession number: AY596279). It was performed as previously described by Liu et al. (2007). Briefly, the PCR reaction was performed in a total volume of $25 \mu \mathrm{l}$ containing $1.75 \mathrm{mM} \mathrm{MgCl} 2,200 \mu \mathrm{M}$ dNTPs, $0.1 \mu \mathrm{M}$ first forward (P1, positions 1-24), $0.5 \mu \mathrm{M}$ second forward (B$\mathrm{P} 2$, positions 367-383), $0.5 \mu \mathrm{M}$ reverse (B-R2, positions 623-606), 2.0 units Taq polymerase (TaKaRa Bio Inc.) and $5.0 \mu \mathrm{l}$ genomic DNA. The PCR reaction conditions had an initial enzyme activation and hot start at $95{ }^{\circ} \mathrm{C}$ for $5 \mathrm{~min}$, followed by the first round amplification consisting of 30 cycles of $94{ }^{\circ} \mathrm{C}$ for $30 \mathrm{~s}, 61^{\circ} \mathrm{C}$ for $30 \mathrm{~s}$ and $72{ }^{\circ} \mathrm{C}$ for $45 \mathrm{~s}$. The second round amplification consisted of 30 cycles of $94{ }^{\circ} \mathrm{C}$ for $30 \mathrm{~s}, 55{ }^{\circ} \mathrm{C}$ for $30 \mathrm{~s}, 72{ }^{\circ} \mathrm{C}$ for $30 \mathrm{~s}$ with a final extension at $72{ }^{\circ} \mathrm{C}$ for $10 \mathrm{~min}$ (Liu et al., 2007). PCR products were visualized using $2 \%$ ethidium bromide-stained agarose gel electrophoresis.

\subsection{Statistical analysis}

Statistical analysis was performed by SAS (version 8.0 SAS Institute). Summary statistics were obtained by crosstabulations of categorical data and statistically significant differences in the proportions of positive samples between the LAMP and semi-nested PCR detection were determined using the chi-square test. The test results were considered significantly different when the $P$-value $<0.01$.

\section{Results}

\subsection{Analytical specificity of the LAMP assay}

Primers F3 and B3 successfully amplified a $197 \mathrm{bp}$ region of the $18 \mathrm{~S}$ rRNA gene of $B$. orientalis when used in a regular PCR. Sequence analysis of the PCR product confirmed that the $B$. orientalis $18 \mathrm{~S}$ rRNA gene segment was amplified. $B$. orientalis DNA demonstrated a typical ladder pattern when subjected to the LAMP assay (Fig. 1). No amplification was seen with any of the other Babesia or
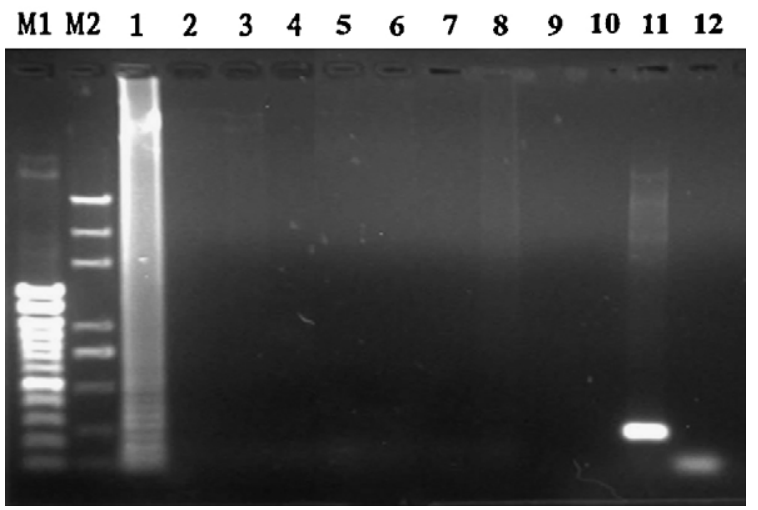

Fig. 1. Specificity of the LAMP primers. M1: 100 bp ladder marker; M2: DL2000 plus marker (100 bp, 250 bp, 500 bp, 750 bp, 1000 bp, 2000 bp, $3000 \mathrm{bp}, 5000 \mathrm{bp}$ ); lane 1: Babesia orientalis; lane 2: B. bovis; lane 3: $\mathrm{B}$. divergens; lane 4: B. bigemina; lane 5: T. mutans; lane 6: T. velifera; lane 7: T. parva; lane 8: uninfected water buffalo DNA; lane 9: African buffalo DNA; lane 10: distilled water as blank control for the LAMP assay; lane 11: regular PCR amplified the entire target sequence using primers F3 and B3; lane 12: distilled water as blank control for the regular PCR.
Table 2

Detection of Babesia orientalis by microscopy, semi-nested PCR and LAMP in experimentally infected water buffalo.

\begin{tabular}{llll}
\hline Days post-infection & Microscopy & Semi-nested PCR & LAMP \\
\hline 0 & - & - & - \\
3 & - & - & + \\
6 & - & + & + \\
9 & + & + & + \\
12 & + & + & + \\
15 & + & + & + \\
18 & + & + & + \\
21 & + & + & + \\
24 & - & + & + \\
27 & - & + & + \\
30 & + & + & + \\
33 & + & + & + \\
36 & - & + & + \\
39 & - & - & + \\
\hline
\end{tabular}

Theileria species. The gold standard negative samples also tested negative as expected. For the detection of positive reactions using SYBR Green I, only tubes containing $B$. orientalis turned green.

\subsection{Evaluation of the LAMP assay using experimentally infected buffalo samples}

B. orientalis was detected by LAMP on day three postinfection (Table 2). With the semi-nested PCR and microscopy, $B$. orientalis was first detected on days six and nine, respectively. The LAMP assay could detect $B$. orientalis consistently up to day 39 post-infection, whereas the semi-nested PCR could only detect it up to day 36. The parasite was difficult to consistently detect microscopically from day 24 post-infection.

\subsection{Detection of B. orientalis from field samples}

A total of 165 randomly selected water buffalo from eight different regions of the Hubei province, south China were tested for the presence of $B$. orientalis using the LAMP assay and semi-nested PCR. Our results show that 30 (18.2\%) of the water buffalo samples tested positive for the presence of $B$. orientalis using the LAMP assay (Table 3 ). Only 13 (7.9\%) tested positive using the semi-nested PCR. Of the 77 samples collected south of the Yangtse River, 24 (31.2\%) tested positive using the LAMP assay, and 12 (15.6\%) using the semi-nested PCR. For the 88 samples collected north of the Yangtse River, 6 (6.8\%) tested

Table 3

Detection of $B$. orientalis from water buffalo samples using the LAMP assay and semi-nested PCR.

\begin{tabular}{lllr}
\hline & $\begin{array}{l}\text { North of } \\
\text { Yangtse River }\end{array}$ & $\begin{array}{l}\text { South of } \\
\text { Yangtse River }\end{array}$ & Total \\
\hline $\begin{array}{l}\text { Semi-nested PCR } \\
\text { Positive }\end{array}$ & 1 & 12 & 13 \\
$\quad$ Negative & 87 & 65 & 152 \\
LAMP & & & \\
$\quad$ Positive & 6 & 24 & 30 \\
$\quad$ Negative & 82 & 53 & 135 \\
Total & 88 & 77 & 165 \\
\hline
\end{tabular}


positive with the LAMP assay and $1(1.1 \%)$ with the seminested PCR.

As indicated, the LAMP assay generally detected higher proportions of positive $B$. orientalis samples than the seminested PCR. This difference in sensitivity was shown to be statistically significant different $\left(\chi^{2}=7.7279, P=0.0083\right)$ as indicated by the chi-square (SAS version 8.0 ) test.

\section{Discussion}

China has the world's second largest water buffalo population. Buffalo babesiosis is a serious threat to water buffalo. It was first reported in 1984 in China (Chen, 1984) to occur in nine provinces (South of China) with a high prevalence in endemic areas, and it was described as $B$. orientalis in 1997 (Liu et al., 1997). A semi-nested PCR assay targeting the 18S rRNA gene was developed for the detection of $B$. orientalis in water buffalo and the potential tick vector $R$. haemaphysaloides (Liu et al., 2007). In this study, we describe the development of a simple, sensitive and cost-efficient loop-mediated isothermal amplification (LAMP) assay for the specific detection of $B$. orientalis in water buffalo samples. Results were compared with that obtained using the semi-nested PCR of Liu et al. (2007).

A set of four primers targeting the V4 hypervariable region of the $18 \mathrm{~S}$ rRNA gene of $B$. orientalis was designed and shown to be $B$. orientalis specific. The specificity of the assay was confirmed as no amplification was seen with any of the other Babesia or Theileria species investigated. The gold standard negative samples also tested negative as expected. Blood samples obtained from $B$. orientalis experimentally infected buffalo were used to compare the sensitivity of the LAMP assay with that of the seminested PCR and microscopic examination of thin blood smears. The LAMP assay was able to detect $B$. orientalis on day three post-infection whereas the semi-nested PCR and microscopy could only detect the parasite on days six and nine, respectively. It has been shown by other authors that microscopic examination of thin blood smears cannot be used to detect Babesia positive animals in the early phase or in the carrier stage of infection, as the number of circulating parasites is too low (Calder et al., 1996). It was, therefore, not unexpected that we had difficulty to microscopically detect $B$. orientalis in the initial stages of infection or that we could not consistently detect the parasite throughout the course of the study. In the case of the semi-nested PCR, Liu et al. (2007) have shown that the semi-nested PCR had a higher sensitivity than microscopical examination and that it could be used to detect carrier animals. With the LAMP assay we were able to detect $B$. orientalis three days before it was detected by semi-nested PCR which highlights that this newly developed assay is even more sensitive than the reported seminested PCR.

The LAMP assay as well as the semi-nested PCR was used to determine the $B$. orientalis infection status of 165 water buffalo sampled from eight different regions of the Hubei province, south China. In a previous study, Liu et al. (2007) have shown that $B$. orientalis infection was prevalent to the south of the Yangtse River, while no $B$. orientalis could be found to the north of the river. The authors speculated that there must be a connection between geographical conditions and the distribution of the tick vector, $R$. haemaphysaloides. Also, that the Yangtse River may be a natural barrier for $B$. orientalis and that due to the establishment of more bridges over the river, that this natural barrier could be potentially destroyed in future. In our study, we have shown that $31.2 \%$ of the samples collected south of the Yangtse River, tested positive for $B$. orientalis infection using the LAMP assay, and $15.6 \%$ using the semi-nested PCR. Of the samples collected north of the Yangtse River, 6.8\% (6 animals) tested positive with the LAMP assay and $1.1 \%$ ( 1 animal) with the semi-nested PCR. This indicates the spread of $B$. orientalis from the south to the north of the Yangtse River and as the role of the Yangtse River as a natural barrier is being eroded. As more bridges are built, there is an increase in the geographical connection between the south and north of the Yangtse River with an increased threat that $B$. orientalis infected animals and vector ticks being transported to previously Babesia-free areas. This maybe lead to serious outbreaks of $B$. orientalis in Babesia-free areas. If the vector ticks $R$. haemaphysaloides were transported and existed in Babesia-free areas, B. orientalis will exist stably in these areas. This poses a serious threat to the water buffalo industry and highlights the importance of developing highly sensitive diagnostic assays for the early diagnosis of B. orientalis.

In summary, we have developed a LAMP assay for the specific detection of $B$. orientalis in water buffalo. The assay has proofed to be specific and more sensitive than the previously described semi-nested PCR (Liu et al., 2007). While buffalo babesiosis caused by $B$. orientalis has not been previously reported to the north of the Yangtse River, our results have shown that $B$. orientalis has spread to the north of the river, which could pose a serious threat to the water buffalo industry.

\section{Acknowledgments}

The study was partially supported by the National Natural Science Foundation of China (NSFC, the grant No. is 30671575), the program for new century excellent talent (NCET06-0668) from Ministry of Education, PR China. It was also partially funded by the South African National Research Foundation (NRF), SA-China cooperation programme (grant no. 67147) awarded to $\mathrm{Dr}$ Marinda C. Oosthuizen. The authors would like to thank the Department of Veterinary Tropical Diseases, Faculty of Veterinary Science, University of Pretoria, South Africa for making available their facilities and Drs Roy Bengis and Dave Cooper for providing African buffalo specimens.

\section{References}

Almeria, S., Castella, J., Ferrer, D., Ortuno, A., Estrada-Pena, A., Gutierrez, J.F., 2001. Bovine piroplasms in Minorca (Belearic Islands, Spain): a comparison of PCR-based and light microscopy detection. Vet. Parasitol. 99, 249-259.

Caccio, S., Camma, C., Onuma, M., Severini, C., 2000. The beta-tubulin gene of Babesia and Theileria parasites is an informative marker for species discrimination. Int. J. Parasitol. 30, 1181-1185. 
Calder, J.A., Reddy, G.R., Chieves, L., Courtney, C.H., Littell, R., Livengood, J.R., Norval, R.A., Smith, C., Dame, J.B., 1996. Monitoring Babesia bovis in cattle by using PCR-based tests. J. Clin. Microbiol. 34, 27482755 .

Chen, S.R., 1984. Babesiosis of buffalo caused by a combination of Babesia bigemina and B. bovis. Hubei J. Vet. Sci. Technol. 8, 38-39 (in Chinese).

Chen, T.Y., 1989. An investigation of babesiosis in buffaloes in Fujian province. Chin. J. Vet. Sci. 15 (3), 5-7 (in Chinese).

Fahrimal, Y., Goff, W.L., Jasmer, D.P., 1992. Detection of Babesia bovis carrier cattle by using polymerase chain reaction amplification of parasite DNA. J. Clin. Microbiol. 30, 1374-1379.

Figueroa, J.V., Chieves, L.P., Johnson, G.S., Buening, G.M., 1993. Multiplex polymerase chain reaction based assay for the detection of Babesia bigemina, Babesia bovis and Anaplasma marginale DNA in bovine blood. Vet. Parasitol. 50, 69-81.

Liu, Q., Zhao, J.L., Zhao, Y.Q., Liu, E.Y., Yao, B.A., Fu, Y., 2005. Study on some molecular characterization of Babesia orientalis. Vet. Parasitol. 130, 191-198.

Liu, Q., Zhou, Y.Q., Zhou, D.N., Liu, E.Y., Du, K., Chen, S.G., Yao, B.A., Zhao, J.L., 2007. Semi-nested PCR detection of Babesia orientalis in its natural hosts Rhipicephalus haemaphysaloides and buffalo. Vet. Parasitol. 143, 260-266.

Liu, Z.L., Ma, L.H., Zhang, G.D., Gao, X.S., 1986. An investigation of babesiosis in buffaloes in Hubei province. Acta Vet. Zootechnica Sin. 17 (1), 49-54 (in Chinese).

Liu, Z.L., Ma, L.H., Gao, X.S., Cheng, X.J., 1987. Study on babesiosis of buffaloes in Hubei Province II. Experimental infection demonstrated Rhipicephalus haemaphysaloides haemaphysaloides to be the vector of babesiosis in buffaloes. Acta Vet. Zootechnica Sin. 18 (3), 173-178 (in Chinese).

Liu, Z.L., Zhao, J.L., Ma, L.H., Yao, B.A., 1997. Babesia orientalis sp.nov. parasitized in buffalo Bubalus babalis in China (Piroplasmida: Babesiidae). Acta Vet. Zootechnica Sin. 28 (1), 84-89 (in Chinese).

Martins, T.M., Pedro, O.C., Caldeira, R.A., do Rosario, V.E., Neves, L., Domingos, A., 2008. Detection of bovine babesiosis in Mozambique by a novel seminested hot-start PCR method. Vet. Parasitol. 153, 225230.

Notomi, T., Okayama, H., Masubuchi, H., Yonekawa, T., Watanabe, K., Amino, N., Hase, T., 2000. Loop-mediated isothermal amplification of DNA. Nucleic Acids Res. 28, 63.

Oliveira-Sequeira, T.C.G., Oliveira, M.C.S., Araujo Jr., J.P., Amarante, A.F.T. 2005. PCR-based detection of Babesia bovis and Babesia bigemina in their natural host Boophilus microplus and cattle. Int. J. Parasitol. 35, 105-111.

Sibeko, K.P., Oosthuizen, M.C., Collins, N.E., Geysen, D., Rambritch, N.E., Latif, A.A., Groeneveld, H.T., Potgieter, F.T., Coetzer, J.A.W., 2008. Development and evaluation of a real-time polymerase chain reaction test for the detection of Theileria parva infections in Cape buffalo (Syncerus caffer) and cattle. Vet. Parasitol. 155, 37-48.

Smeenk, I., Kelly, P.J., Wray, K., Musuka, G., Trees, A.J., Jongejan, F., 2000. Babesia bovis and B. bigemina DNA detected in cattle and ticks from Zimbabwe by polymerase chain reaction. J. S. Afr. Vet. Assoc. 71, 2124

Wagner, G., Cruz, D., Holman, P., Waghela, S., Perrone, J., Shompole, S., Rurangirwa, F., 1992. Non-immunologic methods of diagnosis of babesiosis. Mem. Inst. Oswaldo. Cruz. 87 (Suppl. III), 193-199. 